\title{
Análisis ambiental de los cambios en el uso de las tierras en el partido de Azul (Buenos Aires, Argentina)
}

\author{
Vazquez, P.; L. Zulaica y E. Requesens
}

\begin{abstract}
RESUMEN
Desde el comienzo de la difusión de la soja transgénica a mediados de la década del noventa, la agricultura argentina experimentó una notable expansión territorial con cambios de dominancia entre los principales cultivos y diversas consecuencias ambientales. Este trabajo pretende analizar los cambios de uso de suelo en un partido del centro de la provincia de Buenos Aires (Azul), Argentina, entre 1995 y 2011, a fin de caracterizar el proceso de agriculturización mediante la definición de paisajes. Se utilizaron imágenes satelitales clasificadas de 1995 y 2011, estadísticas oficiales de superficies sembradas por cultivo, estudios antecedentes y se realizaron relevamientos de campo. El estudio realizado sugiere que en el partido se incrementó la superficie agrícola $173 \%$ entre ambos años, en desmedro de las áreas ganaderas. Asimismo, en el período se produjo un reemplazo de trigo por soja como cultivo dominante. El avance agrícola tuvo lugar desde el paisaje de llanuras periserranas hacia los paisajes de serranías y planicies deprimidas. Se considera que el estudio de los cambios en la cobertura y uso del suelo en los paisajes diferenciados permitirá realizar una lectura de los distintos escenarios del proceso de agriculturización, sentando bases para la gestión ambiental del territorio.
\end{abstract}

Palabras clave: agriculturización, sensores remotos, paisajes, impactos ambientales.

Vazquez, P.; L. Zulaica and E. Requesens, 2016. Environmental analysis of land use changes in the district of Azul (Buenos Aires, Argentina). Agriscientia 33 (1): 15-26

\section{SUMMARY}

Ever since transgenic soybean crops began to spread in the mid-90s, agricultural lands have expanded remarkably in Argentina, thus producing changes in the dominance of major crops and bringing about various environmental consequences. This work aims to analyze changes in the use of lands in Azul, a central district of Buenos Aires province, Argentina, from 1995 to 2011, and to characterize the agricultural expansion process (known as "agriculturization") in that district, by means of landscape definition. Classified satellite images for the1995-2011 period, official statistics of sown areas arranged by crop 
type and previous studies were used; field surveys were also conducted. The study suggests that the agricultural area of the district increased by $173 \%$ in the 1995-2011 period, at the expense of livestock areas. Moreover, wheat was replaced by soybean as the dominant crop in the same period. Agricultural expansion occurred from the peri-mountainous plains landscapes to the hills and depressed plains landscapes. The study of changes in land use and land cover in distinct landscapes will enable researchers to interpret the different scenarios of the agricultural expansion process and will lay bases for environmental management of lands.

Keywords: agriculturization, remote sensing, landscapes, environmental impacts.

P. Vazquez: UNCPBA, Facultad de Ciencias Humanas, CESALCONICET. L. Zulaica: UNMdP, Facultad de Arquitectura, Urbanismo y Diseño, IHAM-CONICET. E. Requesens: UNCPBA, Facultad de Agronomía, NUCEVA. Correspondencia a: patriciavazquez@conicet.gov.ar

\section{INTRODUCCIÓN}

El análisis de los cambios en el uso del suelo cobra cada vez más importancia en las investigaciones ambientales, debido a las consecuencias que implican sobre la pérdida de hábitats, diversidad biológica, servicios ambientales y la degradación de la capacidad productiva de los ecosistemas (Rosete Verges et al., 2008). Gran parte de los cambios ocurridos en los ecosistemas terrestres se vinculan con la conversión de la cobertura del suelo y la degradación e intensificación en el uso del terreno (Lambin, 1997; Bocco et al., 2001).

Los cambios en la cobertura y uso de la tierra son considerados como alteraciones en la superficie terrestre, que son el resultado de las actividades humanas; éstas ocasionan efectos en diferentes direcciones, asociadas a procesos ecológicos, socioeconómicos, culturales, entre otros (Lambin \& Meyfroidt, 2009). La cobertura de la tierra se define como una respuesta a un contexto biofísico, que se observa en la superficie; describe diferentes atributos que ocupan un espacio, los cuales pueden derivarse de ambientes naturales producto de la evolución ecológica o a partir de ambientes artificiales creados y mantenidos por el hombre (González Borrero \& Romero Rodríguez, 2013), como es el caso de los agroecosistemas.

En la conversión de ecosistemas nativos en agroecosistemas se manifiestan numerosos problemas ambientales que tienen su origen en la fitosimplificación con fines productivos. En este sentido, existe un consenso científico y social respecto de la importancia que posee la biodiversidad en el funcionamiento y mantenimiento de los ecosistemas (Vara Sánchez \& Cuéllar Padilla, 2013). Como sostiene Gliessman (2007), la diversidad es un elemento esencial para la estabilidad y complejidad de los ecosistemas, no sólo la diversidad de especies sino también de múltiples formas de diversidad que expresan distintos tipos de heterogeneidad espacial, temporal y funcional. La expansión e intensificación agrícola inciden negativamente sobre los distintos tipos de heterogeneidad.

La agricultura de la Argentina en general, y de la región pampeana en particular, ha experimentado una notable expansión a partir de un desarrollo tecnológico basado en cultivos transgénicos, siembra directa, incremento en el uso de fertilizantes y plaguicidas y agricultura de precisión (Satorre, 2005). Por razones fundamentalmente económicas, el cambio tecnológico y la expansión de la superficie cultivada se han concentrado mayormente en el cultivo de soja y ello ha conducido a una simplificación estructural y funcional de los sistemas productivos y de los paisajes agrícolas (Viglizzo et al., 2006; Aizen et al., 2009). Al respecto, Flores \& Sarandon (2014) sostienen que la selección de tecnologías sobre la base de un análisis de costobeneficio simplificado sobreestima la rentabilidad de los sistemas de producción e incentiva la degradación del capital natural al no incluir los costos ambientales generados por la intensificación productiva.

Es importante destacar que el proceso al que se hace referencia no ha sido homogéneo dentro de la región pampeana. Por el contrario, los patrones de expansión agrícola y la susceptibilidad 
ambiental presentan características particulares en las distintas áreas agroecológicas en que se divide dicha región (Viglizzo \& Jobbágy, 2010). El centro y sudeste de la provincia de Buenos Aires están atravesados por el sistema orográfico de Tandilia, que separa dos importantes subregiones de la Pampa Húmeda: la Pampa Deprimida y la Pampa Interserrana (Morello et al., 2000). Por lo anterior, cualquier intento de profundizar el análisis de los cambios en el uso de la tierra y sus implicancias ambientales en este sector de la Pampa Húmeda, debe partir de reconocer la diversidad de ambientes existentes. En este sentido, se destacan como antecedentes los trabajos de Vazquez et al. (2012a; 2014) para la Cuenca del río Quequén Grande (CrQG) en el sudeste bonaerense y de Vazquez \& Zulaica (2014) para el partido de Tandil.

Vazquez et al. (2012a; 2014) analizaron los cambios en el uso de la tierra en la CrQG durante 20 años, en diferentes ambientes geomorfológicos, e identificaron los problemas ambientales más relevantes asociados con dichos cambios a partir de la estimación de indicadores de sustentabilidad. Los resultados muestran que los usos agrícolas aumentaron $(37,7 \%)$ y los ganaderos disminuyeron $(39,9 \%)$. Los ambientes geomorfológicos más perturbados fueron en 1988-1998 las Ilanuras aluviales y lomas de divisorias con lagunas, mientras que en 1998-2008 se destacan las sierras y serranías. En ambos períodos, esta última unidad mencionada registró condiciones críticas en la valoración de indicadores referidos al riesgo de intervención de hábitat, riesgo de contaminación por plaguicidas e impactos sobre el ecosistema. Aplicando un procedimiento metodológico semejante, Vazquez \& Zulaica (2014) comparan las áreas ocupadas por distintos usos del suelo y sus impactos ambientales en la cuenca superior del arroyo Langueyú (CUSAL) y en el partido de Tandil, en el cual se halla inserta, en tres cortes temporales (1988, 2002 y 2010). Entre 1988 y 2010, los usos agrícolas aumentaron significativamente en la CuSAL (159,5\%), mientras que en el partido el aumento fue $39,4 \%$. En consecuencia, los impactos ambientales sobre el medio natural, medidos con indicadores de sustentabilidad, fueron más intensos en la cuenca que en el partido en su conjunto.

El partido de Azul sintetiza la situación del centro bonaerense, en tanto constituye un área mixta que contiene sectores correspondientes a la Pampa Deprimida hacia el norte y sectores correspondientes al sistema de Tandilia hacia el sur. Las características agroecológicas y productivas de cada sector descritas por Requesens (2011) dan cuenta de dos zonas con modelos diferentes: uno con predominancia agrícola hacia el sur y otro con ganadera hacia el norte. En la zona sur se incluyen las sierras del sistema de Tandilia. De acuerdo a los censos agropecuarios de 1988 y 2002, la superficie sembrada incrementó $65 \%$ en ese período (Requesens, 2005). Esta tendencia lleva implícito un proceso de fragmentación progresiva del hábitat natural, que en el sector sur prácticamente ha quedado restringido al ecosistema serrano propiamente dicho. Pero la expansión agrícola se manifiesta también en las tierras planas y anegables que ocupan el norte del partido, aunque con mucha menor frecuencia por la limitada disponibilidad de suelos aptos para cultivos. Estas apreciaciones han sido evidenciadas también sobre la base del uso de imágenes satelitales por Vazquez et al. (2012b) y Vazquez \& Zulaica (2013).

Los antecedentes disponibles sobre el proceso de agriculturización (Manuel-Navarrete \& Gallopin, 2007) en el partido de Azul (Vazquez \& Zulaica, 2013), si bien resultan útiles para una primera aproximación a la problemática planteada, requieren ser complementados con estudios que permitan discriminar ambientalmente la dinámica territorial de los cambios en el uso de la tierra.

En este contexto, el objetivo del presente trabajo consistió en analizar los cambios de uso de suelo en un partido del centro de la provincia de Buenos Aires (Azul), Argentina, entre 1995 y 2011, a fin de caracterizar el proceso de agriculturización mediante la definición de paisajes.

\section{MATERIALES Y MÉTODOS}

\section{Área de estudio}

El partido de Azul se localiza en el centro de la provincia de Buenos Aires, Argentina (Figura 1). Limita al norte con los partidos de Las Flores y Tapalqué, al este con Rauch y Tandil, al oeste con Olavarría y al sur con Benito Juárez. La ciudad cabecera se inserta en la cuenca del arroyo Azul, analizada por Gandini (2005). De acuerdo a la caracterización realizada por el Centro Regional de Agrometeorología FAA-UNICEN, el clima regional es de tipo templado húmedo con influencia oceáni$\mathrm{ca}$, inviernos suaves y veranos cortos y frescos. El régimen de precipitaciones presenta un promedio anual de 900 mm, con una distribución normal y una mayor concentración en el período primaveroestival. Registra un exceso de las precipitaciones sobre la evapotranspiración durante los meses de invierno lo cual, junto a la escasa pendiente y la baja permeabilidad de los suelos en algunas zonas, genera frecuentes inundaciones. Durante el verano puede presentarse un leve déficit hídrico. 


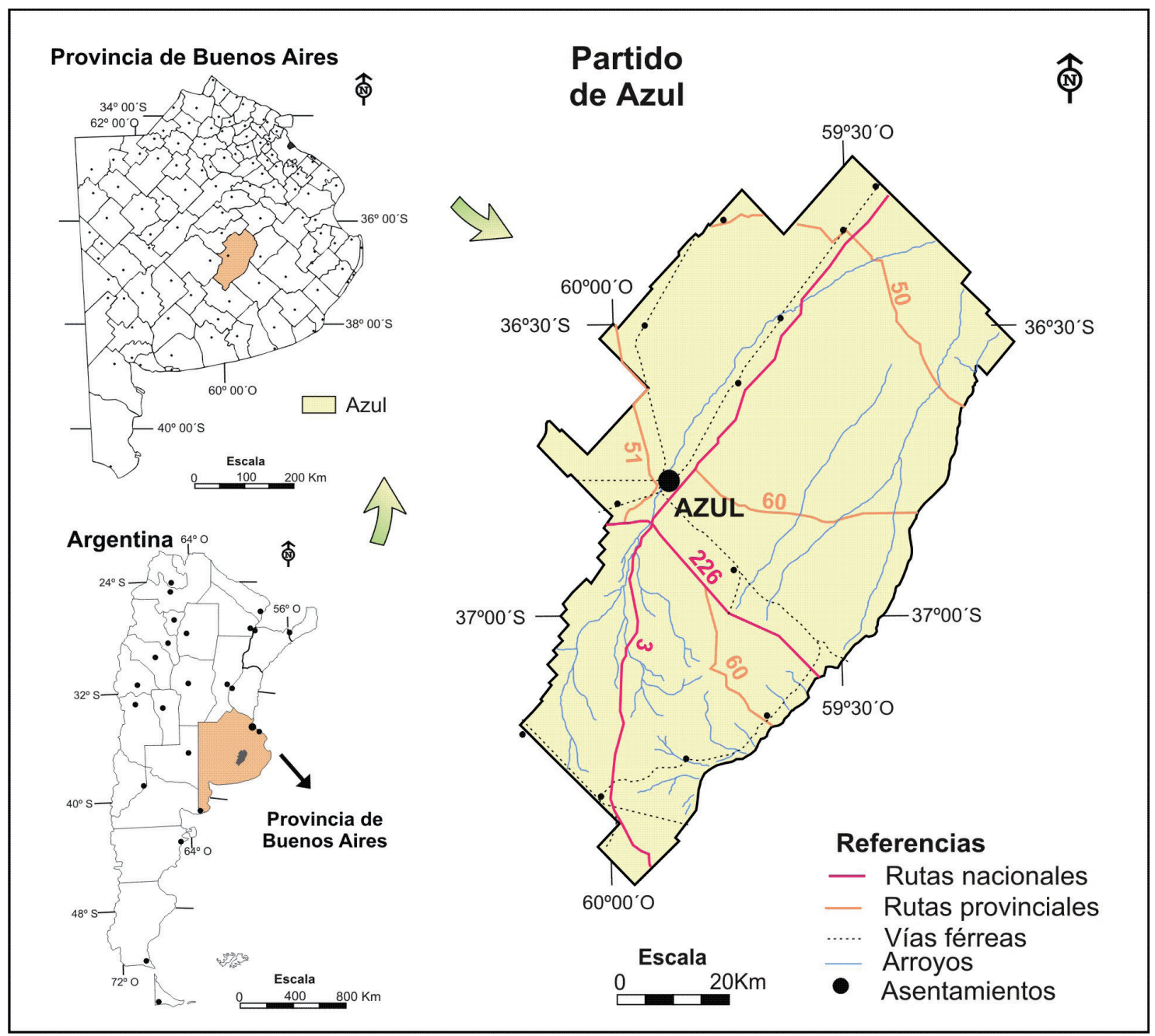

Figura 1. Localización del partido de Azul (Provincia de Buenos Aires, Argentina). Tomado de Vazquez \& Zulaica (2013).

Entre los factores adversos para la agricultura se encuentran también las heladas que, aunque rara vez se producen fuera de época, se caracterizan por su variabilidad. El período libre de heladas oscila entre 123 y 245 días, y no se registran años sin heladas.

Desde el punto de vista fitogeográfico el área de estudio forma parte de la Provincia Pampeana descripta por Cabrera \& Willink (1973) y Cabrera (1976). Estos autores definen como tipo de vegetación dominante a la estepa o pseudoestepa de gramíneas, que forman matas de 0,60 a $1 \mathrm{~m}$ de altura. Agronómicamente, se trata de pastizales naturales que han sido sustituidos por agroecosistemas en vastas áreas del partido, especialmente en aquellas que presentan suelos muy aptos para la agricultura (Argiudoles típicos) localizados en zonas periserranas. La vegetación nativa se conserva mayormente en sectores con severas limita- ciones para la actividad agrícola, como los afloramientos rocosos de las áreas serranas y los sitios con mayor anegabilidad de la Pampa Deprimida.

\section{Procedimiento metodológico}

A fin de analizar los cambios en el uso del suelo originados por el proceso de agriculturización, se obtuvieron cuatro imágenes satelitales correspondientes a los años 1995 y 2011, captadas por el sensor TM de la misión Landsat 5, con Path/Row (225/85 y 225/86), con las siguientes fechas de adquisición: 26/09/1995 (225-85), 26/09/1995 (22586), 26/02/2011 (225-85) y 26/02/2011 (225-86). Las imágenes fueron obtenidas de la página correspondiente al Instituto Nacional de Pesquisas Espaciais (INPE) del Ministerio de Ciencia e Tecnología de Brasil. La primera fecha seleccionada corresponde 
a los momentos previos a la difusión y adopción masiva de la soja transgénica, que aceleró el proceso de agriculturización en Argentina, y la segunda fecha, a un momento de consolidación del esquema productivo que prevalece en la actualidad.

Una vez obtenidas las imágenes se utilizó el Software ENVI 5.1 (Reserch System Inc., Boulder, CO, USA) para su procesamiento. La calibración radiométrica efectuada implicó un proceso en el cual se convirtieron los niveles digitales a nivel de satélite a reflectancia TOA (tope de la atmósfera). Las imágenes Landsat 5 fueron convertidas primero a valores de radiancia (Chander \& Markham, 2003; Chander et al., 2007). La reflectancia TOA fue convertida a reflectancia en superficie, asumiendo una superficie uniforme lambertiana y bajo condiciones libres de nubes (Schroeder et al., 2006; Soudani et al., 2006).

Todas las imágenes fueron llevadas a la proyección UTM-Datum WGS-84-Zona 21 Sur (software ENVI 5.1). Para ello, las imágenes fueron georreferenciadas utilizando como imagen base la provista por el recorte de un mosaico de imágenes del sensor ETM+, obtenido de la página Web http:// www.landcover.org/. El modo de operación de georreferenciación consistió en una técnica basada en obtención de puntos de control entre dos imágenes, lo cual se realizó eligiendo un mínimo de 20 puntos del mismo sector en cada imagen, y a través de una interpolación matricial realizada por el software se corrigieron geométricamente las imágenes con un error de un píxel (Armand, 1995). Seguidamente, se realizaron los mosaicos (ENVI 5.1) correspondientes a cada año seleccionado y se recortaron aplicando una máscara al partido de Azul a partir de un vector que zonifica sus límites políticos. En este caso, se utilizó la composición denominada falso color o infrarrojo color, sobre las bandas correspondientes al infrarrojo cercano, rojo y verde (bandas 4, 3 y 2, respectivamente). La composición seleccionada vuelve más fácil la cartografía de masas vegetales, láminas de agua y usos urbanos (Chuvieco, 2007).

Posteriormente se realizó una clasificación supervisada a partir de conocimiento previo sobre el terreno y tipos de coberturas. Tal conocimiento se obtuvo mediante trabajo de campo, relevamiento de puntos GPS (Global Positioning System), datos de sensores, mapas e informes técnicos y referencias profesionales y de diferentes actores locales, entre otros.

Con este conocimiento como base, se definieron y delimitaron sobre la imagen las áreas de entrenamiento. Se tomaron un total de 35 puntos como áreas de entrenamiento, localizados funda- mentalmente en las inmediaciones de los principales ejes de comunicación (rutas 226, 3, 50, 51, 60 y algunos caminos vecinales). El trabajo de campo se realizó durante 2010-2011.

Luego, en la fase de asignación se aplicó el clasificador de máxima probabilidad. Una vez obtenida la imagen clasificada, se empleó un filtro Median $\left(3^{\star} 3\right)$ que permite mejorar el contraste espacial de la imagen (Chuvieco, 2007). Para ajustar las clases, se utilizaron datos proporcionados por informantes calificados en cada punto obtenido mediante GPS. De esta manera se recabó información acerca de los cultivos sembrados en la fecha en que se obtuvieron las imágenes seleccionadas para el trabajo.

Una vez obtenida una clasificación satisfactoria, es necesario evaluar su precisión (González Iturbe Ahumada, 2001). Para la evaluación de la exactitud de las clasificaciones se utilizó la función de ENVI 5.1 Compute ROI Separability, la cual permitió corroborar que las clases seleccionadas discriminan adecuadamente cada uso del suelo. Se obtuvieron luego los estadísticos de las imágenes clasificadas, es decir, los píxeles por cada clase y se estimó la superficie.

El análisis de los resultados obtenidos a partir de la clasificación de las imágenes se complementó con estimaciones agrícolas aportadas por el Sistema Integrado de Información Agropecuaria del Ministerio de Agricultura, Ganadería y Pesca de la Nación (SIIA), que permitieron profundizar el estudio con datos de superficies sembradas para cada cultivo específico y ver su incidencia en el proceso de agriculturización.

A fin de caracterizar de manera preliminar las diferenciaciones en el avance de la agricultura al interior del partido, se realizó una zonificación de carácter exploratorio que permitió definir paisajes. El término paisaje tiene varias acepciones y su significado ha variado a través del tiempo (Mazzoni, 2014). En este caso, se adopta la conceptualización de Burel \& Baudry (2002) quienes definen al paisaje como un nivel de organización de los sistemas ecológicos superior al ecosistema que se caracteriza esencialmente por su heterogeneidad y por su dinámica, controlada en gran parte por las actividades humanas. En el presente trabajo se tomaron estudios antecedentes realizados en la región por Sánchez et al. (1999) y Sánchez y Zulaica (2002), y se consideraron los criterios de zonificación y la nomenclatura utilizados por estos autores (serranías, llanuras periserranas y planicies deprimidas). Estos antecedentes parten del concepto adoptado por la ecología del paisaje, cuya aplicación permite delimitar, identificar y caracterizar uni- 
dades que presentan cierta homogeneidad interna en la escala de análisis adoptada (1:100.000). Los paisajes del partido de Azul se delimitaron tomando como base cartográfica las cartas topográficas del Instituto Geográfico Militar (IGM) y los límites de las unidades de suelos publicadas por el INTA (1970) en escala 1:50.000. Se integraron los atributos bióticos y abióticos: geomorfológicos, edáficos, condiciones de drenaje y vegetación. Cada uno de estos atributos se representó espacialmente en distintas capas de información utilizando gvSIG (versión 1.11) y se integraron mediante el módulo de geoprocesamiento de este software.

\section{RESULTADOSY DISCUSIÓN}

La Figura 2 muestra los mapas del partido de Azul confeccionados mediante la clasificación de las imágenes satelitales. A partir de los estadísticos de las imágenes clasificadas fue posible cuantificar las superficies asignadas a diferentes actividades y analizar sus tendencias. La superficie predominantemente ganadera pasó de ocupar 511.800 ha en 1995 a 302.800 ha en 2011, lo que representa una caída de $41 \%$. Paralelamente, la superficie dominada por agricultura pasó de
129.000 ha en 1995 a 351.900 ha en 2011, equivalente a un incremento de $173 \%$ (Figuras 3 y 4 ).

Esta disminución de las áreas ganaderas en el partido se asocia directamente al incremento de las superficies agrícolas. Si bien esta expansión, a los fines prácticos, permite aumentar los rindes, conlleva un trasfondo de costos ambientales que generalmente no son tenidos en cuenta.

El reemplazo de ganadería extensiva basada en pastizales naturales por cultivos anuales implica retrotraer el sistema a los estados iniciales de la sucesión ecológica secundaria. En esta situación se maximiza la productividad primaria neta, pero al mismo tiempo se pierden atributos de los estados maduros que resultan fundamentales para mantener la estabilidad del sistema y el equilibrio con el ambiente. Entre tales atributos se destacan la complejidad estructural, los ciclos biológicos prolongados y lentos, los ciclos minerales cerrados con alta conservación de nutrientes y la alta eficiencia energética (Odum, 1969). Por otra parte, el mantenimiento de los sistemas agrícolas lejos del equilibrio natural requiere subsidios energéticos que en algunos casos, como los plaguicidas y fertilizantes sintéticos, reducen la biodiversidad y pueden contaminar el ambiente en caso de no ser

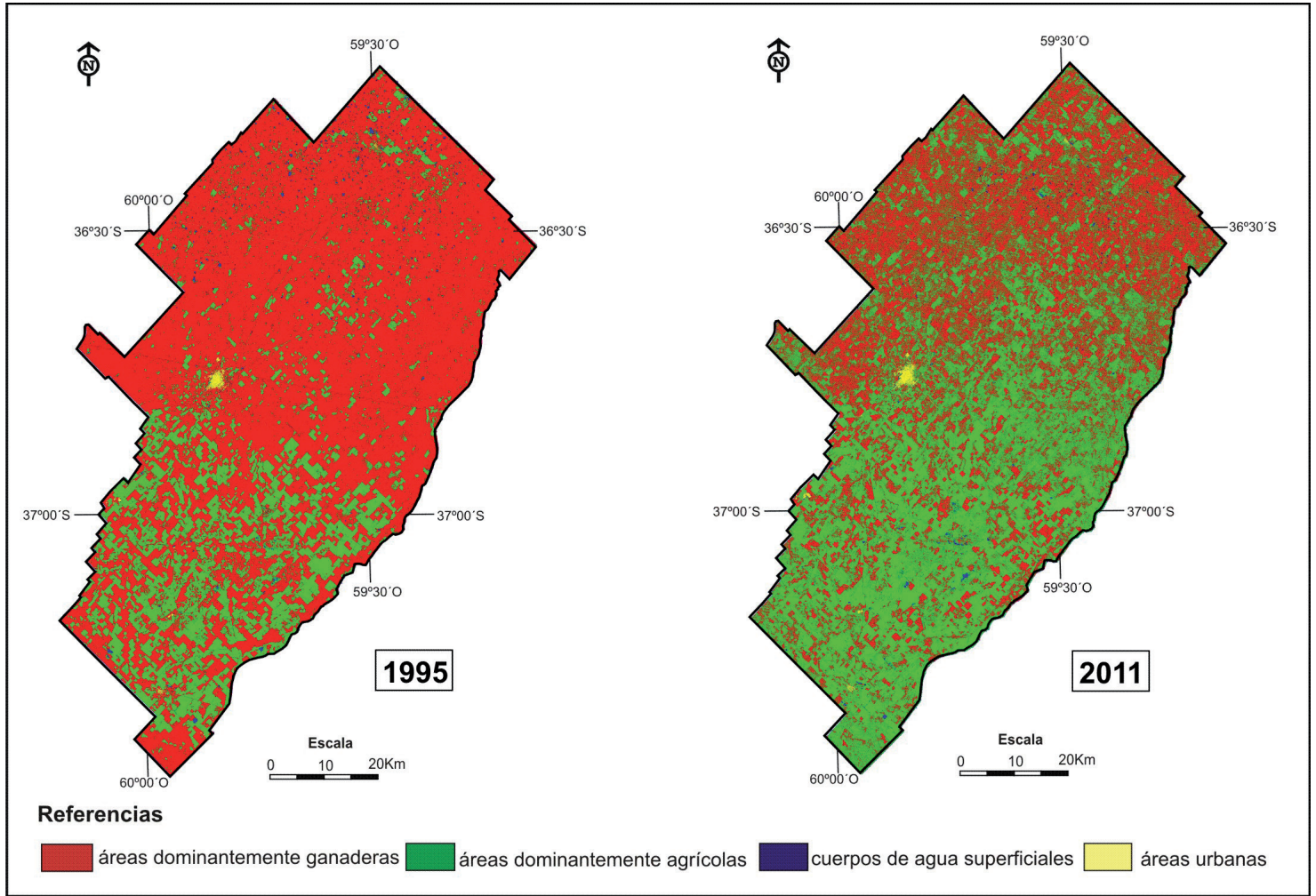

Figura 2. Uso de la tierra en el partido de Azul en los años 1995 y 2011. Mapas confeccionados a partir de imágenes Landsat 5 (TM). 


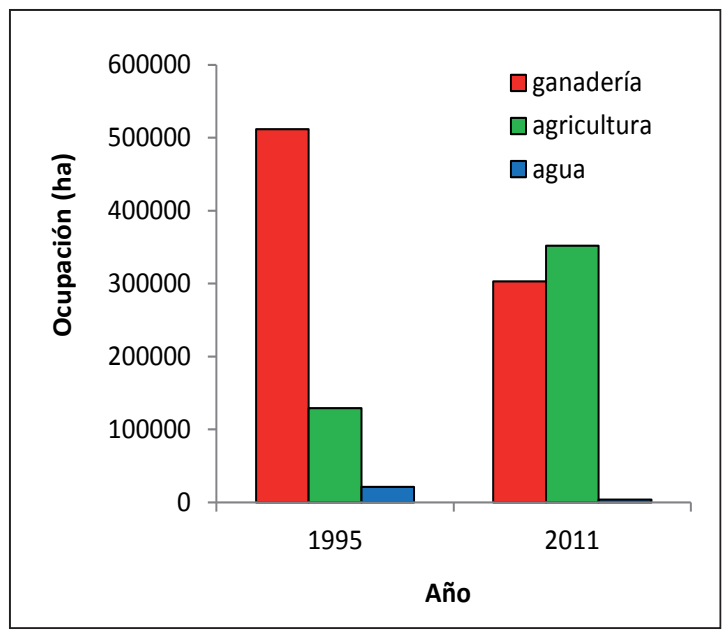

Figura 3. Superficie de usos de la tierra destinada a ganadería, agricultura y cuerpos de agua en 1995 y 2011.

correctamente utilizados (Pengue, 2001; Viglizzo, 2007; Viglizzo y Jobbágy, 2010).

De acuerdo con la FAO (2007) la principal causa de la erosión genética, que implica la pérdida de recursos genéticos mediante la extinción de una variedad de cultivo, es la sustitución de ejemplares autóctonos por variedades mejoradas. Esta baja diversidad dada por el interés sobre pocos cultivos se ve agravada por el hecho de que, en general, se utilizan sólo unas pocas variedades, las más "exitosas". A su vez, la siembra de estas variedades en amplias superficies aumenta la fragilidad del sistema y el riesgo de que el ataque de una plaga pueda provocar efectos devastadores en la producción de alimentos (Sarandon \& Flores, 2014).

Los cuerpos de agua superficial, localizados predominantemente en el sector norte del partido, si bien ocupaban una superficie menor en 1995, equivalente a 21.100 ha, se redujo aún más en 2011, donde ocupaban 3800 ha. Esta reducción de cuerpos de agua superficiales en el período analizado, también influyó en el avance de áreas agrícolas sobre suelos potencialmente inundables, lo cual genera riesgos económicos a los productores (Vazquez, 2013).

El proceso de agriculturización evidenciado en las imágenes clasificadas del partido se relaciona directamente, como sucede en la región, con el avance del cultivo de soja, tal como fue descripto en los antecedentes (Vazquez et al., 2012a; Vazquez \& Zulaica, 2014). En los últimos 25 años, la expansión liderada por la soja ha ocurrido dentro de una matriz tecnológica enmarcada por cultivos transgénicos, siembra directa, uso de fertilizantes y plaguicidas y, en menor medida, agricultura de

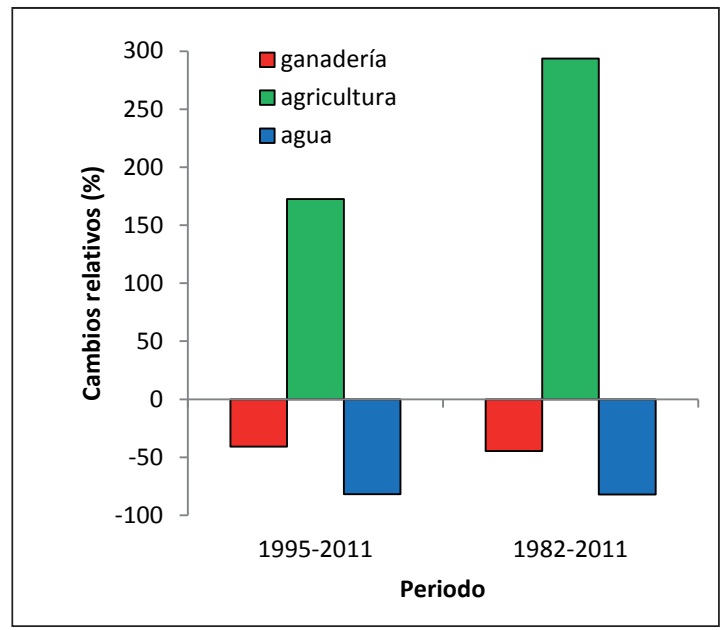

Figura 4. Cambios relativos en la superficie destinada a ganadería, agricultura y cuerpos de agua en 1995 y 2011.

precisión (Viglizzo, 2007). Esto se refleja claramente en el área de estudio. En este sentido es importante destacar que los principales cultivos que se realizaban en el área de estudio a mediados de los '90 tuvieron diferente protagonismo en el incremento de la superficie agrícola. De acuerdo a las estimaciones del Sistema Integrado de Información Agropecuaria del Ministerio de Agricultura, Ganadería y Pesca de la Nación (SIIA), el trigo fue el principal componente agrícola en la campaña 1995/96, seguido de maíz y girasol como cultivos co-dominantes (Figura 5). La soja, que se manifiesta como un cultivo emergente en la campaña 1995/96, se transformó en el cultivo claramente dominante en la campaña 2011/12. En esta última, además, la cebada cervecera desplazó al tri-

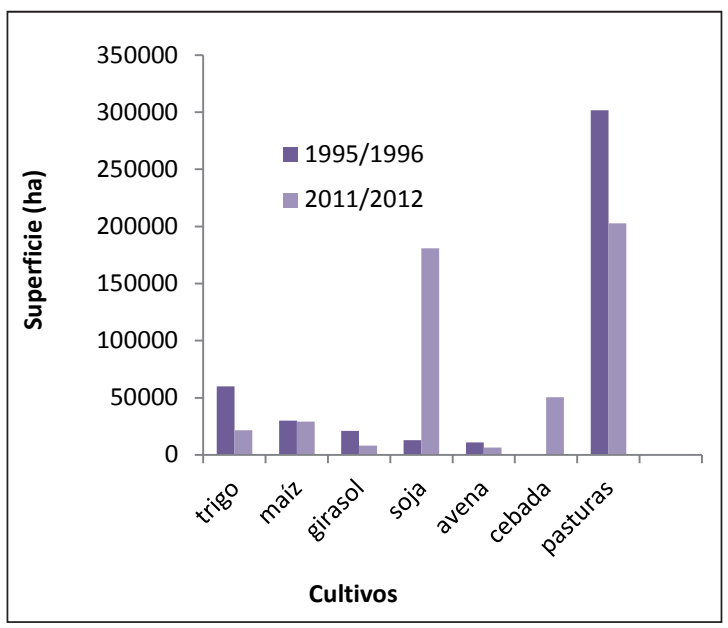

Figura 5. Superficie agrícola-ganadera del partido de Azul, 19952011, elaborado según datos del SIIA. 
go como principal cultivo de invierno. Tendencias similares fueron también reflejadas en establecimientos agropecuarios en el vecino partido de Tandil (Seehaus \& Requesens, 2014) y en el partido de Benito Juárez (Sequeira et al., 2015).

Desde el punto de vista agroecológico el reemplazo de trigo por soja implica cambios en la dinámica de los principales nutrientes y un aumento de su exportación. La soja requiere 80 kg de nitrógeno por tonelada de grano producida y exhibe un índice de cosecha de 0,75 para este nutriente, contra un requerimiento de $30 \mathrm{~kg}$ con un índice de cosecha de 0,66 en trigo. Con respecto a fósforo, la soja requiere $8 \mathrm{~kg}$ por tonelada de grano producida y presenta un índice de cosecha de 0,84, contra un requerimiento de $5 \mathrm{~kg}$ con un índice de cosecha de 0,75 en trigo; las diferencias son aún más notorias en los casos de potasio, azufre y calcio (Dreccer et al., 2003; García, 2005). Al elevado consumo y exportación en granos de nutrientes esenciales por parte de la soja, debe sumarse la escasa reposición de carbono asociada al bajo volumen de su rastrojo. Con el tiempo, esto último conduce a una pérdida progresiva en el contenido de materia orgánica del suelo y de ello puede inferirse un deterioro de su estructura física (Vázquez et al., 1990; Casas, 1998; Álvarez et al., 2012).

Las imágenes clasificadas, el trabajo de campo y las entrevistas realizadas ponen en evidencia que el proceso de agriculturización se manifiesta de manera diferenciada al interior del partido. Para analizar de manera preliminar esas diferenciaciones, se realizó una zonificación del partido en la que se definieron tres paisajes: serranías, llanuras periserranas y planicies deprimidas (Figura 6). Las serranías integran cerros, laderas serranas y lomadas altas de las formaciones geológicas del sistema de Tandilia (Teruggi y Kilmurray, 1975). Además de numerosos afloramientos, las diferentes superficies geomórficas asocian suelos poco profundos (Hapludoles líticos) en los que crecen diferentes comunidades herbáceas, integradas por mono y dicotiledóneas, y ocasionalmente arbustales (Frangi, 1975). En las pendientes medias y bajas aparecen los subgrupos Argiudoles líticos y Argiudoles típicos. En las serranías, que ocupan casi un 3\% de la superficie del partido, se localizan las nacientes de una red hidrográfica de alcance regional. El drenaje es rápido como consecuencia de las pendientes, que rondan entre 10 y $70 \%$, y alturas que superan los $200 \mathrm{msnm}$. En este paisaje las actividades predominantes son ganadero-agrícolas. En sitios con afloramientos rocosos o en áreas con contactos líticos a escasa profundidad se preserva la vegetación nativa.

Al disminuir las alturas y pendientes, las se- rranías derivan en las Ilanuras periserranas. Esta unidad abarca casi el $30 \%$ de la superficie del partido y está conformada por relieves suavemente ondulados y ondulados con pendientes de 2 a 5\%. Contienen suelos profundos, aunque a veces interrumpidos por la presencia de tosca, y buenas condiciones de drenaje externo e interno. Predominan Argiudoles típicos bien drenados, asociando Hapludoles líticos, Argiudoles líticos y/o Hapludoles tapto árgicos en lomas pronunciadas y Argialboles argiácuicos, Argiudoles ácuicos, Natracualfes mólicos y/o complejos indiferenciados en depresiones y vías de drenaje. Dada su aptitud agroecológica, estas áreas han sido fuertemente sustituidas por cultivos. Previo a su conversión extensiva en agroecosistemas, se caracterizaban por la presencia de pastizales en los que abundaban gramíneas de los géneros Stipa y Piptochaetium. Las actividades predominantes son las agrícolas.

En altitudes menores, aproximadamente 160170 msnm, las llanuras periserranas se continúan con las planicies deprimidas. En esta unidad, que alcanza la mayor extensión del partido (entre 60 y $70 \%$ ), el drenaje es lento como consecuencia de las escasas pendientes que no superan el 0,2\%. Los suelos predominantes son Natracuoles típicos, Natracualfes típicos y mólicos. No obstante, en las lomas aparecen Hapludoles tapto árgicos, tapto nátricos y Argiudoles típicos, en tanto que en las depresiones y vías de escurrimiento son comunes los complejos de suelos indiferenciados. Si bien con distintos grados de alteración por el pastoreo vacuno, muchas áreas de estas planicies conservan pastizales nativos dado que el bajo potencial de escurrimiento superficial, las cubetas con agua periódica o permanente y los suelos anegables impiden o dificultan seriamente el desarrollo de actividades agrícolas. En cambio, en las áreas con mejores condiciones de drenaje, frecuentemente la vegetación natural es sustituida por cultivos.

La superposición de los paisajes definidos sobre los usos en el período estudiado, muestra que en 1995 la agricultura había comenzado a expandirse de manera generalizada en el paisaje correspondiente a las llanuras periserranas del partido. Asimismo, comenzaba a penetrar en las planicies deprimidas del centro y norte del partido, donde se perciben algunos sitios aislados dentro de este paisaje. En 2011, la agricultura ocupaba prácticamente la totalidad de las llanuras periserranas y serranías, excepto las áreas con afloramientos rocosos y pendientes pronunciadas de este último paisaje. Evidenciaba, además, un avance considerable sobre las planicies deprimidas del centro del partido y en menor medida sobre el mismo paisaje pero en el extremo norte, que presenta las máxi- 


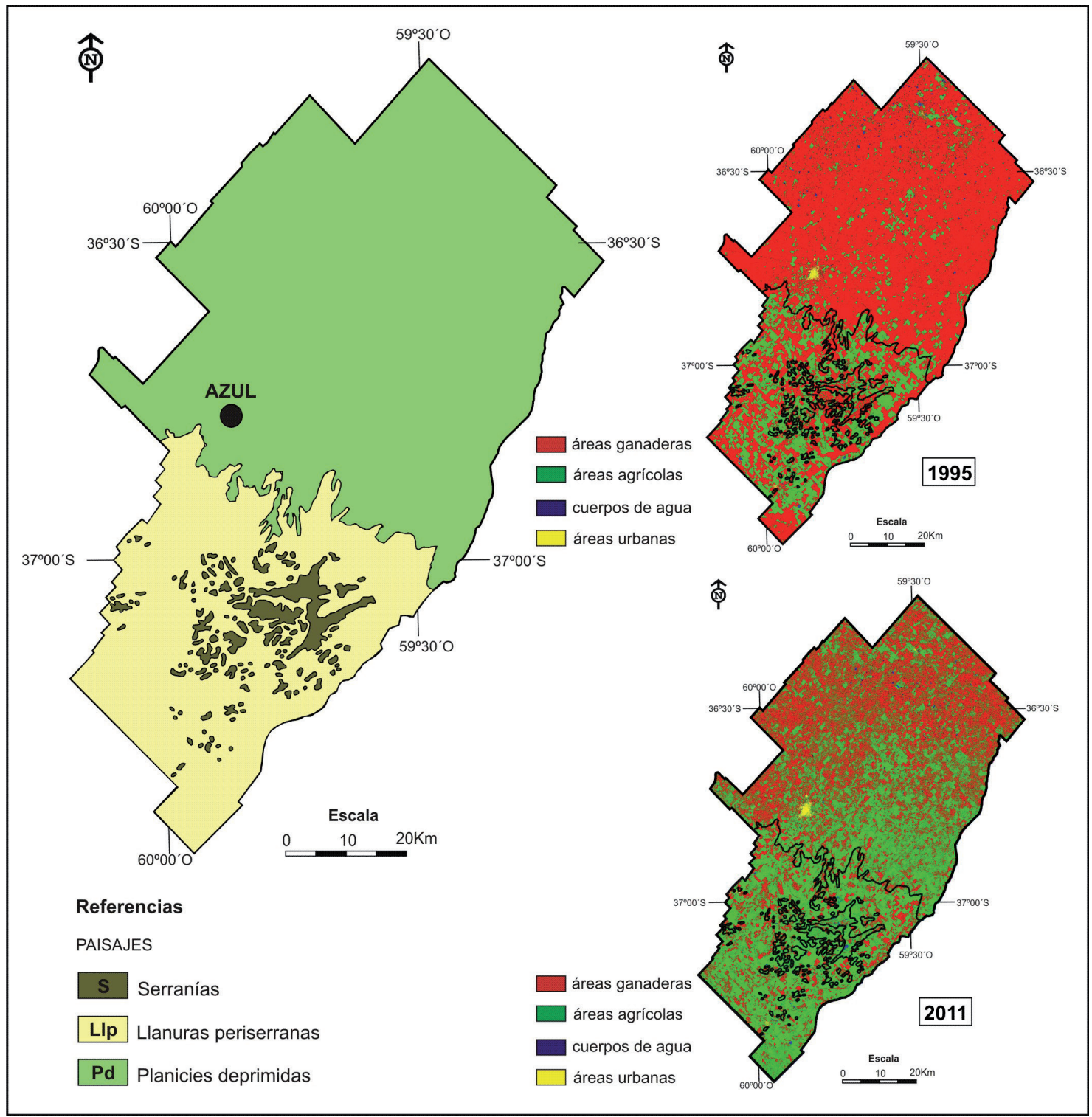

Figura 6. Paisajes del partido de Azul y usos del suelo.

mas condiciones de anegabilidad.

Con base en los resultados obtenidos es posible aseverar que desde mediados de la década del noventa, y siguiendo las tendencias nacionales y regionales, el partido de Azul ha experimentado un proceso de expansión agrícola iniciado previamente pero potenciado a partir del lanzamiento de la soja transgénica. La imagen clasificada de 1995 muestra que el paisaje de llanuras periserranas representa el área donde se inició y consolidó la expansión agrícola. Un segundo flujo expansivo, evidenciado en la imagen de 2011, ocurrió en las serranías y en la zona central de las planicies deprimidas. Por último, el sector norte de las planicies deprimidas es el que mayormente ha resistido el avance de la agricultura hasta el momento.

La dinámica del proceso de agriculturización ha estado acompañada por un aumento en los riesgos ambientales, asociados en primer lugar al reemplazo de sistemas ganaderos basados en pastizales naturales por sistemas agrícolas y, en segundo lugar, a los cambios en la dominancia de cultivos con diferentes características ecofisiológicas. 
Finalmente, se destaca la necesidad de realizar estudios más profundos que permitan clasificar las imágenes separando las clases de uso en los paisajes definidos y estimar los impactos ambientales por cada uno de ellos. En este sentido, el estudio de los cambios en la cobertura y uso del suelo en los paisajes diferenciados permitirá realizar una lectura de los distintos escenarios del proceso de agriculturización, sentando bases para la gestión ambiental del territorio.

\section{BIBLIOGRAFÍA}

Aizen, M.A., L.A. Garibaldi y M. Dondo, 2009. Expansión de la soja y diversidad de la agricultura argentina. Ecología Austral 19: 45-54.

Álvarez, R.; J. Berhongaray Paepe, M.R. Mendoza, H.S. Steinbach, C. Caribe y R. Cantet, 2012. Productividad, fertilidad y secuestro de carbono en suelos pampeanos: efecto del uso agrícola. Anales de la Academia Nacional de Agronomía y Veterinaria, t. 66: 381-426.

Armand, M., 1995. Télédétection, urbanisme et aménagement. Groupement pour le développement de la télédétection aérospatiale (GDTA), Toulouse.

Bocco, G.; M. Mendoza and A. Velázquez. 2001. Remote sensing and GIS-based regional geomorphological mapping. A tool for land use planning in developing countries. Geomorphology 39(3-4): 211-219.

Burel, F. y J. Baudry, 2002. Ecología del Paisaje: conceptos, métodos y aplicaciones. Editorial Mundi-Prensa, Madrid.

Cabrera, A.L, 1976. Regiones Fitogeográficas Argentinas. Enciclopedia Argentina de Agricultura y Jardinería. Editorial ACME (Tomo II), Buenos Aires.

Cabrera, A. y A. Willink, 1973. Biogeografía de América Latina. Secretaría General de la Organización de los Estados Americanos, Washington.

Casas, R.R. 1998. Causas y evidencia de la degradación de los suelos en la Región Pampeana. En Hacia esa agricultura productiva y sostenible en la pampa. En David Rockefeller (Ed.), Center for Latin American Studies, Harvard University, Consejo Profesional de Ingeniería Agronómica. Editorial Orientación Gráfica S.R.L. Buenos Aires.

Chander, G. and B. Markham, 2003. Revised Landsat-5 TM Radiometric Calibration Procedures and Postcalibration Dynamic Ranges. Transactions on Geoscience and Remote Sensing, IEEE. 41(11): 2674-2677.

Chander, G.; B. Markham and J. Barsi, 2007. Revised Landsat-5 Thematic Mapper Radiometric Calibration. Geoscience and Remote Sensing Letters, IEEE 4(3):490-494.

Chuvieco, E., 2007. Teledetección Ambiental. La obser- vación de la tierra desde el espacio. Ediciones Ariel Ciencia, Barcelona.

Colombres, M., 2012. El trigo cede ante la cebada cervecera. Diario La Nación. Suplemento de economía, Buenos Aires.

Dreccer, M.; R. Ruiz, G. Maddonni y E. Satorre, 2003. Bases ecofisiológicas de la nutrición en los cultivos de grano. Capítulo 18. En Satorre, E.; R. Benech Arnold, G. Slafer, E. De la Fuente, D. Miralles, M. Otegui. y R. Savin (Eds.). Producción de granos. Bases funcionales para su manejo, Editorial Facultad de Agronomía. 767 pp.

Frangi, J., 1975. Sinopsis de las Comunidades Vegetales y el Medio de las Sierras de Tandil (Provincia de Buenos Aires). Boletín de la Sociedad Argentina de Botánica, Volumen XV, No 4. pp. 293-319.

Flores, C. y S. Sarandón, 2014. Sustentabilidad ecológica vs. Rentabilidad económica: el análisis económico de la sustentabilidad. Capítulo 3. En Sarandón, S. y C. Flores (Eds.): Agroecología: bases teóricas para el diseño y manejo de agroecosistemas sustentables. Editorial Edulp, La Plata. 466 pp.

FAO (Food and Agriculture Organization of the United Nations), 2007. El estado mundial de la agricultura y la alimentación. Colección FAO: Agricultura № 38. Roma.

Gandini, M., 2005. Zonas homogéneas de la cuenca del arroyo del Azul: algunos aspectos de su dinámica analizados usando sensores remotos y SIG. Tesis doctoral, Facultad de Ciencias Exactas y Naturales, UBA.

García, F., 2005. Soja. Criterios para el manejo de la fertilización del cultivo. Informaciones Agronómicas del Cono Sur 27:1-6. INPOFOS Cono Sur. Acassuso, Buenos Aires, Argentina.

Gliessman S.R., 2007. Agroecology: The ecology of sustainable food Systems. USA. CRC Press.

González-Iturbe Ahumada, J. 2001. Sistemas de información geográfica y percepción remota aplicados a la conservación de los recursos naturales. En: Encuentro de Laboratorios de Geomática, 1, México D. F.

González Borrero, L. H. y A.P. Romero Rodríguez. 2013. Análisis multitemporal de los cambios de la cobertura de la tierra e incidencia del cultivo de palma en el territorio del municipio de Villanueva Casanare. Trabajo de grado para optar al título de Magister en Gestión Ambiental. Pontificia Universidad Javeriana. Facultad de Estudios Ambientales y Rurales. Maestría en Gestión Ambiental. Bogotá DC. 81 pp.

Instituto Nacional de Pesquisas Espaciais (INPE) del Ministerio de Ciencia e Tecnología de Brasil. Web http:// www.inpe.br/, marzo 2014.

INTA, 1970. Carta de Suelos de la República Argentina. Instituto Nacional de Tecnología Agropecuaria, Buenos Aires. 
Lambin, E.F., 1997. Modelling deforestation processes: a review tropical ecosystem environment observations by satellites, European Commission Joint Research Centre- Institute for Remote Sensing Applications-European Space Agency, Luxembourg, TREE Series B., Research Report $N^{\circ} 1$

Lambin, E.F. and P. Meyfroidtb. 2011. Global land use change, economic globalization, and the looming land scarcity. 108 (9):3465-3472.

Manuel-Navarrete, D. y G. Gallopin. 2007. Integración de políticas, sostenibilidad y agriculturización en la pampa argentina y áreas extrapampeanas. Santiago de Chile, Editorial CEPAL (Comisión Económica para América Latina y el Caribe). 1-34.

Mazzoni, E., 2014. Unidades de paisaje como base para la organización y gestión territorial. Estudios Socioterritoriales. Revista de Geografía. 16(2): 51-81.

Morello, J.; G. Buzai, C. Baxendale, S. Matteucci, A. Rodríguez, R. Godagnone y R. Casas, 2000. Urbanización y consumo de tierra fértil. Revista Ciencia Hoy 10(55):50-61.

NASA, 2014. Programa Landsat. <http://landsat.gsfc. nasa.gov/?page_id=9> Consultada el 10/09/2014.

Odum, E.P., 1969. The strategy of ecosystem development. Science, 164, 262-270.

Pengue, W., 2001. Expansión de la soja en Argentina. Globalización, desarrollo agropecuario e ingeniería genética: un modelo para armar. En Revista Seedling.

Posada, E.; H. Ramírez Daza y N. Espejo Delgado, 2012. Manual de prácticas de percepción remota con el programa ERDAS IMAGINE 2011. Instituto Geográfico Agustín Codazzi (IGAC). Bogotá, pp. 1-154.

Requesens, E., 2005. Ambiente, uso de la tierra y agrodiversidad en el paisaje serrano y periserrano del Partido de Azul. Actas del $66^{\circ}$ Congreso Nacional de Geografía, 257-264.

Requesens, E., 2011. Integración agroecológica del partido de Azul. Capítulo V. En Requesens, E. (coord.) Bases agroambientales para un desarrollo sustentable del partido de Azul. Docuprint S.A., Buenos Aires. $136 \mathrm{pp}$.

Rosete Vergés, F.A.; J.L. Pérez Damián y G. Bocco. 2008. Contribución al análisis del cambio de uso del suelo y vegetación (1978-2000) en la Península de Baja California, México. Revista Investigación Ambiental, 1(1): 70-82.

Sánchez, R.; G. Mattus y L. Zulaica, 1999. Compartimentación ecológica y ambiental del partido de Tandil (provincia de Buenos Aires). En Ambiental '99. Programa de Estudios Ambientales, Universidad Nacional de San Juan. San Juan. 338-346 pp.

Sánchez, R. y L. Zulaica. 2002. Ordenamiento morfoedáfico de los sistemas ecológico-paisajísticos del Par- tido de Tandil (Provincia de Buenos Aires). En Contribuciones Científicas (Sociedad Argentina de Estudios Geográficos), Buenos Aires. 387-402.

Sarandon, S. y C. Flores, 2014. Agroecología: bases teóricas para el diseño y manejo de Agroecosistemas sustentables. La Plata, Editorial Universidad Nacional de La Plata.

Satorre, E., 2005, Cambios tecnológicos en la agricultura actual. En Oesterheld, M. (Ed.), La transformación de la agricultura argentina, Ciencia Hoy, 24-31.

Seehaus, M. y E. Requesens, 2014. Agriculturización y diversidad productiva en la llanura periserrana del centro-sudeste bonaerense. Revista Facultad de Agronomía, La Plata, 113(2):100-106.

Sequeira, N.; P. Vazquez y L. Zulaica. 2015. Consecuencias ambientales de la expansión agrícola en el Partido de Benito Juárez (Buenos Aires, Argentina), en el período 2003-2011. Revista Geoaraguaia, 5(2):27-49.

Schroeder, T.A.; W.B. Cohen, C. Song, M.J. Canty and Z. Yang, 2006. Radiometric correction of multi-temporal Landsat data for characterization of early successional forest patterns in western Oregon. Remote Sensing of Environment 103:16-26

Sistema Integrado de Información Agropecuaria del Ministerio de Agricultura, Ganadería y Pesca de la Nación (SIIA). Web: www.siia.gov.ar, marzo 2014.

Sobrino, J.A., 2000. Teledetección. Universidad de Valencia, Valencia.

Soudani, K.; C. Francois, G. Le Maire, V. Le Dantec and E. Dufrene, 2006. Comparative analysis of IKONOS, SPOT, and ETM+ data for leaf area index estimation in temperate coniferouns, and deciduos forest stands. Remote Sensing of Environment 102:161-175.

Teruggi, M.E. y J.O. Kilmurray, 1975. Tandilia. En VI Congreso Geológico Argentino Relatorio Geología de la Provincia de Buenos Aires, Buenos Aires. pp. 55-77.

Vara Sánchez, I. y M. Cuéllar Padilla, 2013. Biodiversidad cultivada: una cuestión de coevolución y transdisciplinariedad. Ecosistemas. 22(1):5-9.

Vázquez, M.E; L.A. Berasategui, E.R. Chamorro, L.A. Tanquini y L.A. Barberis. 1990. Evolución de la estabilidad estructural y diferentes propiedades químicas según el uso de los suelos en tres áreas de la pradera pampeana. Ciencia del Suelo 8: 203-210.

Vazquez, P.; Sacido M. y L. Zulaica, 2012a. Técnicas de análisis para el ordenamiento territorial de cuencas agropecuarias: aplicaciones en la Pampa Austral, Argentina. Scripta Nova 92(XVI).

Vazquez, P.; Zulaica L. y E. Requesens, 2012b. Análisis del proceso de agriculturización en el partido de Azul (provincia de Buenos Aires), mediante el uso de sensores remotos (1984-2011). En Congreso Argentino de Teledetección, Instituto de Investigación en Inge- 
niería Ambiental (UNSAM), CONAE, IAFE-CONICET, Alta Gracia.

Vazquez, P., 2013. Comparación de índices de estrés hídrico, a partir de información captada por el sensor MODIS, en la Región Pampeana Argentina. Revista Cuadernos Geográficos de la Universidad de Granada. Cuadernos Geográficos 52 (1):1-23.

Vazquez, P. y L. Zulaica, 2013. Intensificación agrícola y pérdida de servicios ambientales en el partido de Azul (provincia de Buenos Aires, Argentina) entre 20022010. Revista Sociedade \& Natureza 25(3):543-556.

Vazquez, P. and L. Zulaica, 2014. Agriculturization and environmental impacts in a representative area of the ecoregion of the Pampas, Argentina. Brazilian Geographical Journal: Geosciences and Humanities research medium 5(1):20-45.

Vazquez, P.; L. Zulaica y M. Sacido, 2014. Indicadores de sustentabilidad en las unidades agroecológicas de la Cuenca del río Quequén Grande (Argentina). Campo-Territorio, Revista de Geografía Agraria 9(19): 118-148.
Viglizzo, E., 2007. Desafíos y oportunidades de la expansión agrícola en Argentina. En Martínez-Ortiz U. y L. Tamborini (Eds.), Producción Agropecuaria y Medio Ambiente. Propuestas Compartidas para su Sustentabilidad Fundación Vida Silvestre Argentina, Buenos Aires, Argentina. 12-42.

Viglizzo, E.F.; F. Frank, J. Bernardos and C.S. De Buschiazzo, 2006. A Rapid Method For Assessing the Environmental Performance of Commercial Farms in the Pampas of Argentina Environmental Monitoring and Assessment, 117: 109-134.

Viglizzo, E. y E. Jobbágy, 2010. Expansión de la frontera agropecuaria en Argentina y su impacto ecológicoambiental. Ediciones INTA, Buenos Aires. 102 pp.

Viglizzo, E.; L. Carreño, H. Pereyra, F. Ricard, J. Clatt y D. Pincén, 2010. Dinámica de la frontera agropecuaria y cambio tecnológico. En Viglizzo, E. y E. Jobbágy (Eds.): Expansión de la frontera agropecuaria en Argentina y su impacto ecológico-ambiental. Ediciones INTA, Buenos Aires. 102 pp. 